\title{
A Cross-Sectional Study Assessing Depression and Healthcare Barriers among Urban Pakistani Women
}

\author{
Marina Haque1), Alina Haque'), Allysha Choudhury3), Roland Alexander Blackwood4)
}

\author{
1) Office for Health Equity and Inclusion at the School of Medicine and Department of Health \\ Management and Policy at the School of Public Health, University of Michigan \\ 2) Ross School of Business, University of Michigan \\ 3)Bloomberg School of Public Health, Johns Hopkins University \\ 4) Office for Health Equity and Inclusion at the School of Medicine and Department of Pediatric \\ Infectious Disease, University of Michigan
}

\section{ABSTRACT}

Background: Few studies have assessed depression amongst Pakistani women, particularly in more upscale communities where many traditional risk factors for depression and associated treatment are greatly reduced. Therefore, this study sought to examine depression prevalence in a highly developed sector of Islamabad, factors associated with depression, and the association between depression and barriers to accessing healthcare.

Subjects and Method: In 2016, a cross-sectional pilot study was conducted in Islamabad using convenience sampling. The survey design was based on the Pakistan Demographic Health Survey and included the Center for Epidemiological Studies Depression (CESD) scale. 93 women filled out the entire questionnaire.

Results: The prevalence of depression was unanticipated at $78 \%$; $53 \%$ of these women sampled had major depression. 22\% of women reported ever having spoken to a provider about their mental health. $41 \%$ of women further reported that their mental health negatively impacted their decision to receive care. The only independent risk factor for depression was the diagnosis of another disease. Indicators of poor-socioeconomic status, however, were consistently associated with higher depression likelihood. A robust multivariable regression analysis showed an association between a higher number of self-reported barriers to accessing care and higher depression scale scores $(\mathrm{p}<0.05)$.

Conclusion: A high burden of untreated depression likely exists amongst Pakistani women from urban regions despite a relatively higher prevalence of healthcare resources. Improving mental health disparities in urban settings throughout Southwest and South Asia will require not only increased screening and treatment of patients, but also removal of physical and psychological barriers faced in accessing care.

Keywords: mental health, access barrier, women's health, health equity

\section{Correspondence:}

Marina Haque. Office for Health Equity and Inclusion at the School of Medicine and Department of Health Management and Policy at the School of Public Health, University of Michigan 5101 Medical Sciences I Building 22535 Fuller Drive, Novi, MI 48374 USA. Email: Marinaha@umich.edu. Mobile: + 1 (248) 7673096.

\section{Cite this as:}

Haque M, Haque A, Choudhury A, Blackwood RA (2020). A Cross-Sectional Study Assessing Depression and Associated Healthcare Barriers among Urban Pakistani Women. J Epidemiol Public Health. 05(02): 168-181. https://doi.org/10.26911/jepublichealth.2020.05.02.05.

c) (i) (2) Journal of Epidemiology and Public Healthis licensed under a Creative Commons EY NG SA Attribution-NonCommercial-ShareAlike 4.o International License.

\section{BACKGROUND}

Although very few studies have assessed mental health in Pakistan, the prevalence of mental disorders in Pakistan over the past fifteen years is believed to have increased to alarming levels (Karim et al., 2004; Khalily, 
2011). Various factors are assumed to be responsible, such as the persistent political turmoil and social upheaval that largely escalated post 2001 (Shah et al., 2014).

Depression specifically is estimated to affect between $25 \%$ to $72 \%$ of Pakistani women (Reza and Khan, 2003). In fact, it is considered the most important health disorder affecting women globally (Hirani et al., 2010). Researchers have hypothesized that gender disadvantage may strongly influence mental health, as many Pakistani women exhibit less control over their lives than men (Ali et al., 2013; Kidwai, 2014).

Barriers faced in accessing healthcare are also greater amongst women, which is why understanding their needs is important to creating viable interventions (Qadir et al., 2011). Furthermore, although depression is often treatable, it has a substantial treatment gap worldwide, with estimates as high as 90\% in developing nations (Cuijpers et al., 2013; Shah et al., 2014).

While data on the prevalence of depression in Pakistani communities is scant, even less is known about the illness in well-to-do urban centers. Understanding the burden of mental illness amongst highly developed communities like Islamabad is of great importance because these centers can greatly influence public and private sector development and growth nationally. Prominent risk factors for mental health are also greatly diminished there, such as gender disparities and diminished access to healthcare and education (Shah et al., 2014).

Thus, the objective of this study was foremost to assess the prevalence of depression amongst women in a developed, relatively safe urban sector of Pakistan, and second, to assess factors associated with increased likelihood of depression and its association with healthcare barriers.
SUBJECTS AND METHOD

\section{Study Design}

Following the obtainment of an IRB Exemption status from a local United States Institutional Review Board and approval from local leaders in Islamabad, an anonymous, community based cross-sectional pilot study was carried out in the I-8 sector of Islamabad for two weeks between May and June 2016.

Because security precautions throughout Islamabad are particularly high, random clustering during survey administration was not possible. Instead, key informants were used to gather informants in conjunction with the snowball technique, a commonly used research method where participants subsequently refer other participants. Convenience sampling and/or revised sampling techniques have commonly been used in several different community wide studies in Pakistan for similar reasons (Khan, 1999; National Institute of Population Studies, 2013).

Approximately 18 women of different sub-ethnicities and faiths from the I-8 sector helped gather participants throughout various private and public venues. Persons who were illiterate and wanted to participate in the survey were encouraged to meet the researcher at a pre-determined location in I-8, where a trained member of the research team was available to read aloud the survey. Apart from a 200 rupee reimbursement for travel (roughly \$2 USD), no incentive for the study was given. Research was conducted according to the ethical principles of the Declaration of Helsinki.

\section{Population and Sample}

Inclusion criterion was any women within I-8 who identified as 18 or older and was able to provide informed consent for the study prior to its conduction. Women below age 18 , unable to provide informed consent, 
or outside of I-8 were excluded from participation. Relevant socio-demographic information regarding participants is included in Table 1.

In terms of the study site, I- 8 is an affluent residential neighborhood in Islamabad, chosen primarily for its safety and close proximity to many healthcare facilities and educational institutions (Government of Pakistan, 2016; Shaikh et al., 2014). Choosing this site allowed accomplishment of study objectives more easily. The association of health care accessibility with depression prevalence was better able to be assessed here as the confounding effect of unavailability of care was mildly diminished here. I-8, in fact, borders a prominent hospital district as well as the city of Rawalpindi where there are more than 100 healthcare units (USAID, 2005).

The primary study objective was to determine depression prevalence in an area where traditional depression risk factors are substantially diminished compared to the rest of Pakistan. This facilitated the research team's ability to achieve the second objective, which was to assess for factors associated with increased depression likelyhood beyond socioeconomic barriers to accessing care (Kidwai, 2014; National Institute of Population Studies, 2013). The third objective was to assess clinically depressed versus non-clinically depressed women's perceived access to healthcare.

\section{Study Variables}

Primary study variables assessed consist of demographics, indices of socioeconomic status, experiences within healthcare, and depression scores. Relevant socio-demographic information, including income and literacy levels, is provided in Table 1. Healthcare variables include self-rated health, mental health treatment, and problems accessing healthcare (Table 2). Addi- tional healthcare variables include decision-making, healthcare access prompt score, support in seeking healthcare, perception of local hospital quality, and presence of self-reported health conditions (Table 3).

4. Operational Definition of Variables Demographic variables include selfreported elements such as age (continuous variable, defined by years), household income level (ordinal variable, sorted into four monthly ranges in Pakistani Rupees: under 10000, between 10000-25000, 25001-50000, >5000), and literacy status (binary variable).

Self-reported variables regarding healthcare included identity of the primary decision maker regarding a woman's healthcare decisions, a woman's ability to make decisions for her own healthcare, and barriers to accessing healthcare (attaining permission to solicit treatment, attaining money for healthcare, distance to healthcare facility, not wanting to go to a healthcare facility alone, not feeling safe inside a healthcare facility, not feeling as if one deserved care or that care would be useless, and not feeling comfortable with a provider of the opposite gender).

Healthcare access prompt scores were also created based off of a participant's answers to how many of the nine healthcare prompts she said she would solicit healthcare. Women additionally self-reported presence of health conditions (binary variable that indicates presence of physical or mental health conditions for which respondent may require treatment). They also reported their perception of local healthcare facility quality on a fixed-choice five point scale from poor to excellent (ordinal variable).

Depressive symptoms were assessed via the Center for Epidemiological Studies 
Haque et al./ Depression and healthcare barriers among urban Pakistani women

Depression Scale assessment tool and responses summated on a o-60 point scale. As described further in the next section, to ensure high specificity and sensitivity cut off scores were then used to define the following mental health categories: no clinical depression, minor to moderate clinical depression, and major clinical depression.

\section{Partner or family support of seeking} health care was defined as individual perception of a participant's support status in seeking healthcare, in a fixed-choice scale (strongly agree to strongly disagree).

\section{Study Instruments}

Researchers used a self-administered questionnaire informed by literature review and modeled off the Pakistani Demographic Health Survey (DHS); this is a well-established questionnaire created in consultation with key stakeholders to collate data representative of Pakistan. The mental health questionnaire incorporated into the questionnaire was the Center for Epidemiological Studies-Depression Scale (CESD), an internationally recognized and validated depression screening tool with strong predictive value of minor and major depression (Thomas et al., 2001). A translated CESD tool was used as most psychiatric screening tools that exist in Urdu test for a variety of mental disorders as opposed to depression alone (Ahmer et al., 2007; Mumford et al., 2000).

CESD has also successfully been used in many diverse and multilingual settings similar to Islamabad, and results could be compared to depression surveys worldwide (Malakouti et al., 2015; Radloff, 1977). Finally, CESD has 20 questions assessing depressive symptoms on a 4 point scale, allowing respondents greater flexibility with their responses. To ensure high specificity and sensitivity, a cut off score of 16 was used to define clinical depression; scores between 16 to 26 indicated minor to moderate clinical depression; and a score of 27 was used to define major clinical depression (Geisser et al., 1997).

Women were additionally presented common medical scenarios and asked whether or not they would solicit formal medical attention in those situations to shed light on their health-seeking behavior. All of these situations were chosen as they represent common scenarios women globally may find themselves in and are the largest contributors to mortality for Pakistani women (University of Washington, 2018).

The complete study instrument underwent multiple rounds of revisions; reviewers included several local Pakistanis and physicians. Modifications included adding in more quantifiable survey responses and questions representative to the participant pool. The study was initially designed in English, translated into Urdu, and back-translated in accord- ance with standard translating procedures (Rahman et al., 2003). It was then pre-tested and revised before formal administration. Questions regarding pregnancy or child health prompts were asked only to those identifying as mothers.

\section{Data Analysis}

Overall, 120 surveys were distributed and the survey return rate was $85.8 \%$. 93 participants had filled out the entire questionnaire, including the CESD scale. Data were analyzed using Microsoft Excel 2016 and Stata 14.2. Exploratory and descriptive data analyses were run for all variables to check for assumptions of normality as well as to look for outliers and missing data. Income was converted to quintile categories as seen in Table I.

Education was divided into three categories based on years of schooling obtained. Participant answers were analyzed grossly 
Haque et al./ Depression and healthcare barriers among urban Pakistani women

as well as categorized by depression scale score and evaluated for significance. A final multivariable Poisson regression with robust variance was run to produce risk ratios of potential depression risk factors that have been previously established in the literature. These included age, income level, literacy status, presence of self-reported health conditions, partner or family support for seeking health care, primary health care decision maker, number of health care access barriers, health care prompt score, and perception of self-reported health. A description of all variables used in the final regression can be seen in Appendix A.

\section{Research ethics}

The study was carried out following the obtainment of an IRB Exemption status from a local United States Institutional Review Board and approval from local leaders in Islamabad in accordance with ethical guidelines.

\section{RESULTS}

Defining clinical depression based on CESD score, this study found a $78.5 \%$ (73 women) overall depression rate. $53.4 \%$ (39 women) of these women had scores indicative of major clinical depression (Figure 1). Table 1 depicts depression prevalence amongst different demographic sub-groups, and includes significant predictors of depression based on univariate analysis. Prevalence of depression amongst different groups based on self-rated health, mental health treatment, and barriers to care are further depicted in Table 2. Women who were clinically depressed were nearly two to three times more likely to face most of the listed barriers as hindrances to accessing care.

\section{A. Univariate analysis}

Table 1 showed depression prevalence.

\section{B. The result of multivariate analysis}

The regression model used to predict depression risk is depicted in Table III. By controlling for socioeconomic variables, this analysis showed that only known disease comorbidity was independently predictive of depression score. Variables such as age, number of health care barriers, willingness to access healthcare services, and perceived quality of local health care system did not have significant impact on probability of depression. Still, these variables can and do play can a role in a woman's life. For example, women had 9\% less risk of being clinically depressed with each increasing household economic bracket (see Table 1). Further, women in the lowest income bracket were 10.0 times more likely to have diagnostic symptoms of major clinical depression than women in the highest income bracket.

The associations between depression and marital and familial relationships were also assessed. Although statistically insignificant ( $p>0.05$ ), slightly negative associations with depression likelihood were found for the following variables: a woman's relationship status, her duration of marriage, whether or not she had a family member or partner supportive of her seeking medical care, whether or not she made her own healthcare decisions, and her number of children. While these associations did not independently alter depression scores, participants reported that these variables likely affect their daily stress levels and their ability to seek mental health care. For instance, women who reported partner support in maintaining their health had a $17 \%$ decreased relative risk of depression. 
Haque et al./ Depression and healthcare barriers among urban Pakistani women

Table 1. Depression prevalence

\begin{tabular}{|c|c|c|c|c|}
\hline $\begin{array}{c}\text { Participant } \\
\text { Demographics }\end{array}$ & $\mathbf{N}$ & $\begin{array}{l}\text { Depressed } \\
\text { (\%) }\end{array}$ & $\begin{array}{c}\text { Mild to } \\
\text { Moderate } \\
\text { Depression (\%) }\end{array}$ & $\begin{array}{c}\text { Major } \\
\text { Depression } \\
(\%)\end{array}$ \\
\hline \multicolumn{5}{|l|}{ Place Raised } \\
\hline Native to Islamabad (non-migrant) & 38 & 71.05 & 44.74 & 26.32 \\
\hline Migrated to Islamabad & 55 & 83.64 & 30.91 & 52.73 \\
\hline \multicolumn{5}{|l|}{ Age } \\
\hline 18-24 years old & 27 & 74.07 & 40.74 & 33.33 \\
\hline 25-44 years old & 43 & 79.07 & 32.56 & 46.51 \\
\hline 45-59 years old & 18 & 83.33 & $33 \cdot 33$ & 50.00 \\
\hline$\geq 60$ years old & 5 & 80.00 & 60.00 & 20.00 \\
\hline \multicolumn{5}{|l|}{ Marital Status } \\
\hline Married & 52 & 73.08 & 34.62 & 38.46 \\
\hline Widowed/Divorced/Separated & 12 & 100 & 41.67 & 58.33 \\
\hline Never married & 29 & 79.31 & 37.93 & 41.38 \\
\hline \multicolumn{5}{|l|}{ Housing Status } \\
\hline Employer's home & 22 & 85.00 & 55.00 & 30.00 \\
\hline Own home & 16 & 80.00 & 27.27 & 35.00 \\
\hline Family home & 19 & 57.14 & 28.57 & 28.57 \\
\hline Rent & 30 & 85.71 & 25.00 & 60.71 \\
\hline Other & 2 & 100.00 & 0.00 & 100.00 \\
\hline \multicolumn{5}{|l|}{ Education Attained } \\
\hline No schooling & 32 & 93.75 & 31.25 & 62.50 \\
\hline Some schooling & 19 & 89.47 & 36.84 & 52.63 \\
\hline Higher level education & 42 & 61.90 & 40.48 & 21.43 \\
\hline \multicolumn{5}{|l|}{ Occupation } \\
\hline Employed for wages & 65 & 87.69 & 33.85 & 53.85 \\
\hline Student & 9 & 66.67 & $55 \cdot 56$ & 11.11 \\
\hline Not employed & 19 & 52.63 & 36.84 & $15 \cdot 79$ \\
\hline \multicolumn{5}{|l|}{ Type of work } \\
\hline Housemaid & 47 & 93.62 & 34.04 & $59 \cdot 57$ \\
\hline Teacher & 4 & 100.00 & 25.00 & 75.00 \\
\hline Other & 18 & 61.11 & $33 \cdot 33$ & 27.78 \\
\hline \multicolumn{5}{|l|}{$\begin{array}{l}\text { Monthly household income } \\
\text { (Pakistani Rupees) }\end{array}$} \\
\hline Under 10000 ( $\$ 95$ USD) & 39 & 92.31 & 25.64 & 66.67 \\
\hline $10000-25000(\sim 94-\$ 238$ USD $)$ & 28 & 78.57 & 39.29 & 39.29 \\
\hline $25001-50000(\sim 238-\$ 477$ USD) & 5 & 80.00 & 60.00 & 20.00 \\
\hline $50001+(\sim 477+$ USD $)$ & 15 & $53 \cdot 33$ & 46.67 & 6.67 \\
\hline \multicolumn{5}{|l|}{ Ethnicity } \\
\hline Punjabi & 79 & 79.75 & 32.91 & 46.84 \\
\hline Pakthun & 5 & 80.00 & 40.00 & 20.00 \\
\hline Migrant "muhajir" & 4 & 75.00 & 50.00 & 25.00 \\
\hline Kashmiri, Pahari, Other & 5 & 80.00 & 80.00 & 0.00 \\
\hline \multicolumn{5}{|l|}{ Native Language } \\
\hline Punjabi & 65 & 87.69 & 29.23 & 58.46 \\
\hline Urdu & 19 & 57.89 & 57.89 & 0.00 \\
\hline Pashto & 4 & 75.00 & 50.00 & 25.00 \\
\hline Gabr, Pahari, Saraiki & 4 & 50.00 & 50.00 & 0.00 \\
\hline \multicolumn{5}{|l|}{ Literacy } \\
\hline Literate & 56 & 67.86 & 37.50 & 30.36 \\
\hline Illiterate & 37 & 94.59 & 35.14 & 59.46 \\
\hline
\end{tabular}


Haque et al./ Depression and healthcare barriers among urban Pakistani women

Table 2. The associations between depression, self-rated health, mental health treatment, and barriers to healthcare access

\begin{tabular}{|c|c|c|c|c|}
\hline \multirow{2}{*}{ Independent Variables } & \multicolumn{2}{|c|}{ Depressed (D) } & \multicolumn{2}{|c|}{ Not Depressed (ND) } \\
\hline & $\mathbf{N}$ & $\%$ & $\mathbf{N}$ & $\%$ \\
\hline \multicolumn{5}{|l|}{ Self-Rated Health } \\
\hline Does not believe self in good health & 39 & $53 \cdot 42$ & 2 & 10.00 \\
\hline Mental Health Treatment & & & & \\
\hline $\begin{array}{l}\text { Spoke with provider about depressive } \\
\text { symptoms }\end{array}$ & 15 & 21.43 & 5 & 26.32 \\
\hline $\begin{array}{l}\text { View their depressive symptoms as a } \\
\text { barrier to seeking care }\end{array}$ & 27 & 38.57 & 8 & 22.86 \\
\hline \multicolumn{5}{|l|}{ Problems in Accessing Healthcare } \\
\hline Getting permission to go for treatment & 43 & 59.72 & 8 & 40.00 \\
\hline Getting money for advice or treatment & 54 & 73.97 & 6 & 30.00 \\
\hline Distance to health facility & 71 & 63.38 & 5 & 25.00 \\
\hline Not wanting to go alone & 44 & 61.11 & 8 & 40.00 \\
\hline Not feeling safe inside facility & 40 & 55.56 & 4 & 20.00 \\
\hline $\begin{array}{l}\text { Not feeling as if they deserved care or } \\
\text { that care would be useless }\end{array}$ & 43 & 60.56 & 7 & 35.00 \\
\hline $\begin{array}{l}\text { Not comfortable with a provider of the } \\
\text { opposite gender }\end{array}$ & 37 & 51.39 & 9 & 45.00 \\
\hline
\end{tabular}

a Depression $\approx$ No Depression $\approx$ Mild to Moderate Depression $\approx$ Major Depression

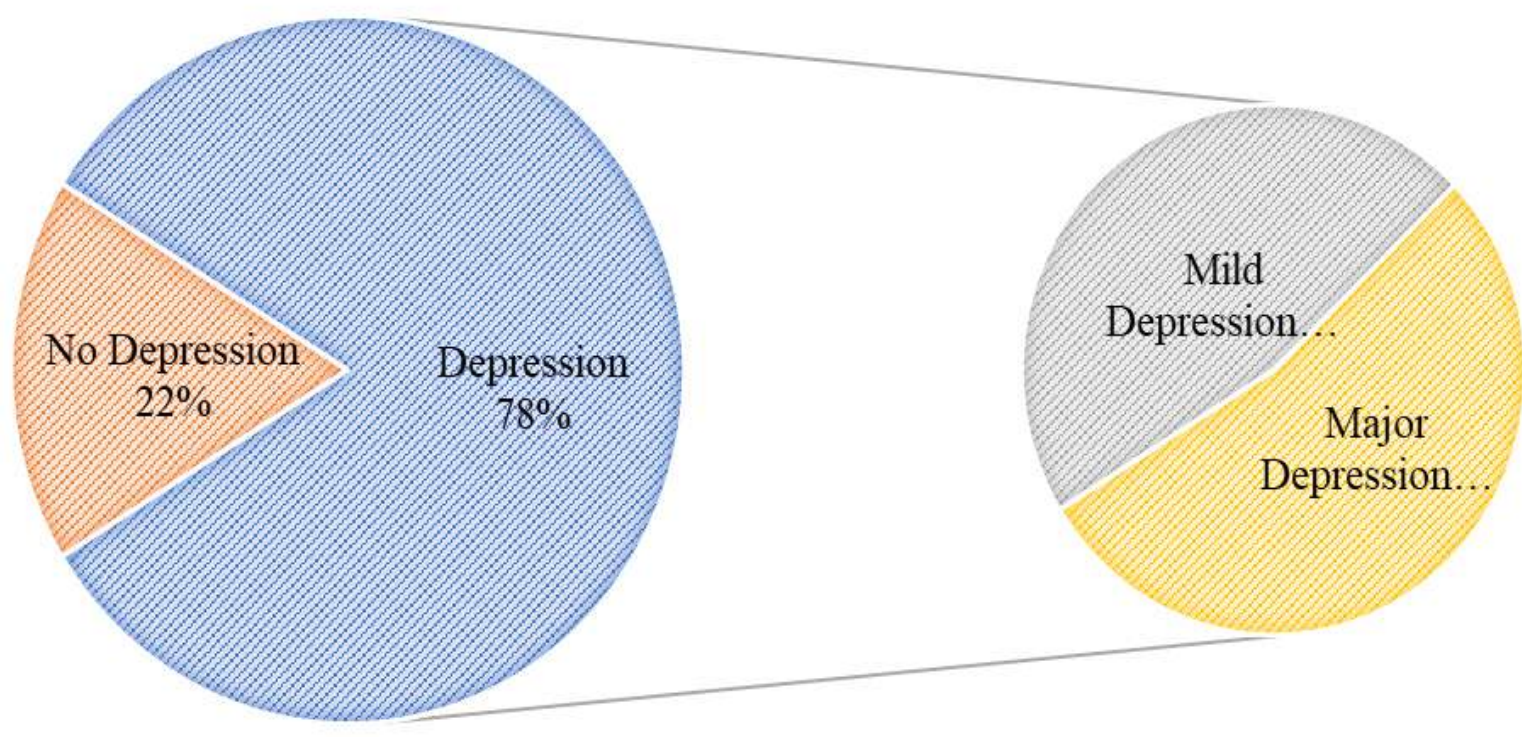

Figure 1. Prevalence of clinical depression

Figure 1 illustrates the overall prevalence of clinical depression in the study sample. The second pie chart depicts that amongst women who screened positive, $53 \%$ met the definition for major depressive disorder. 
Haque et al./ Depression and healthcare barriers among urban Pakistani women

Table 3. Multivariable negative binomial model of risk ratios to predict likelihood of depression.

\begin{tabular}{|c|c|c|}
\hline Independent variables & $\begin{array}{l}\text { Crude Risk Ratio } \\
\text { (95\% CI) }\end{array}$ & $\begin{array}{c}\text { Adjusted Risk } \\
\text { Ratio } \\
\text { (95\% CI) } \\
\end{array}$ \\
\hline \multicolumn{3}{|l|}{ Primary Health care decision maker for self } \\
\hline Self & Ref. & Ref. \\
\hline Self and Husband Jointly & $1.11(0.78,1.58)$ & $1.09(0.81,1.46)$ \\
\hline Husband or Mother-in-law & $1.30(1.01,1.67)$ & $1.24(0.96,1.62)$ \\
\hline Self's family & $1.13(0.83,1.54)$ & $1.10(0.71,1.72)$ \\
\hline Age (year) & $1.00(0.99,1.01)$ & $1.00(0.99,1.01)$ \\
\hline $\begin{array}{l}\text { Number of self-reported health care access } \\
\text { barriers }\end{array}$ & $1.06(1.01,1.12)$ & $0.99(0.93,1.06)$ \\
\hline Health care access prompt score & $1.01(0.97,1.06)$ & $1.03(0.98,1.07)$ \\
\hline Income level & $0.88(0.79,0.98)$ & $0.91(0.79,1.04)$ \\
\hline Literacy status & $0.72(0.59,0.87)$ & $0.83(0.64,1.07)$ \\
\hline Presence of self-reported health condition(s) & $1.18(0.95,1.47)$ & $1.14(0.92,1.42)$ \\
\hline Perception of local hospital quality & $0.99(0.79,1.25)$ & $1.06(0.85,1.31)$ \\
\hline Partner or family support of seeking health care & $0.83(0.66,1.04)$ & $0.84(0.64,1.09)$ \\
\hline
\end{tabular}

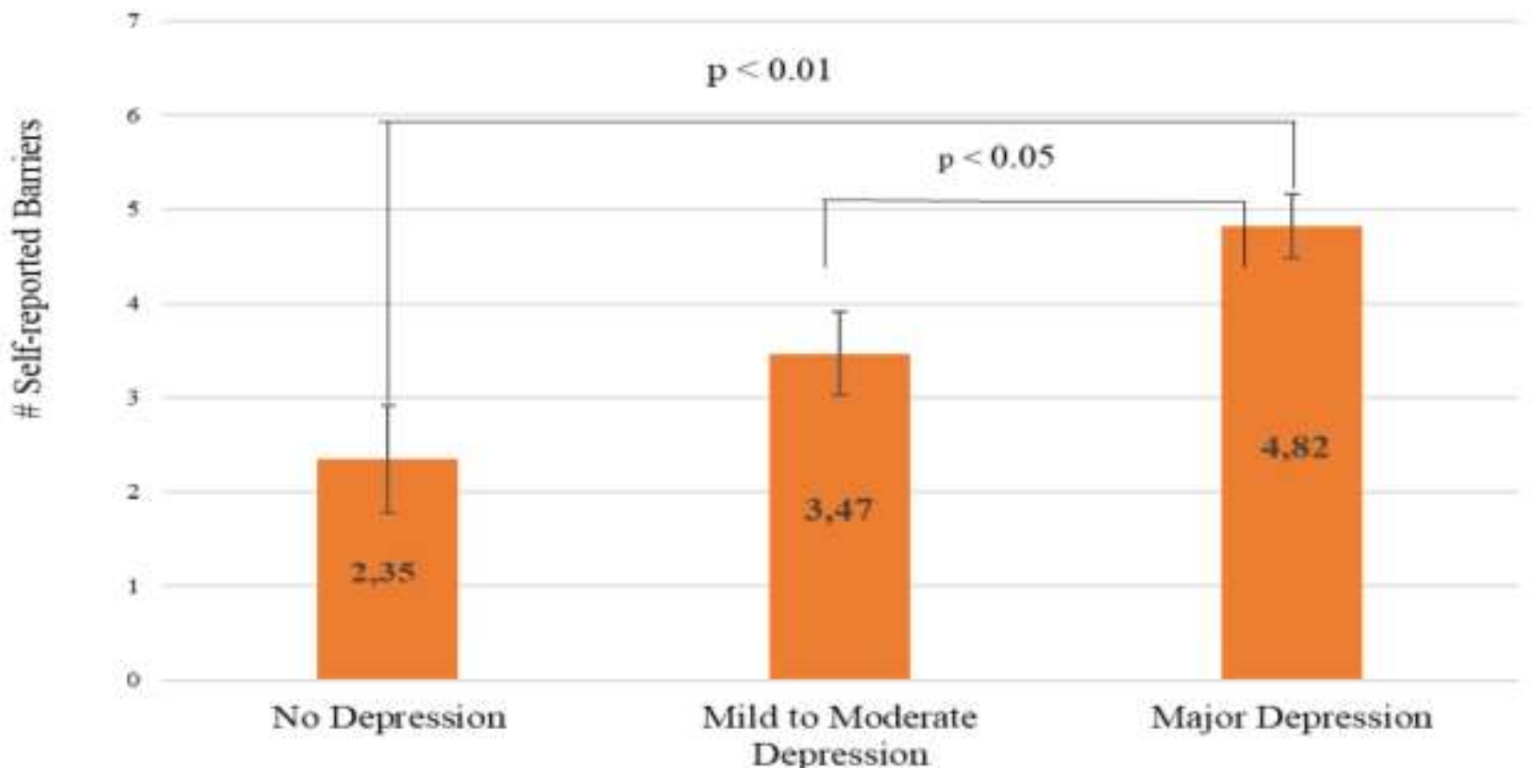

Figure 2. Mean of self-reported healthcare access barriers

Figure 2 depicted that women for without depression $(n=20)$, the average number of barriers was 2.35 (Mean= 2.35; $\mathrm{SD}=2.54)$. Means also differed for women with mild-moderate depression (Mean= $3.47 ; \mathrm{SD}=2.57)$, and major depression $(\mathrm{Mean}=4.82 ; \mathrm{SD}=2.11)$.

\section{DISCUSSION}

Given the diminished traditional risk factors for depression in Islamabad in comparison to the many other regions in South and Southwest Asia, the prevalence of depression at $78.5 \%$ (73 women) within this highly developed community was unantici- 
pated, especially as a slight majority of these women had symptoms characteristic of major clinical depression. Analyses indicated that many positive associations exist between indices of lower socioeconomic status and higher depression scale scores. Such variables include limited education, illiteracy, poverty, and lack of home ownership. No single socioeconomic variable has an independent effect on a woman's depression risk, however, because these factors are social determinants of health that likely act collectively to affect a person's likelihood of depression. These findings are unsurprising because the confounding effects of poverty are a wellknown risk factor for psychiatric morbidity (Husain et al., 2000; Kidwai, 2014; Naeem et al., 2003).

Some unexpected findings in the study, however, were that several factors perceived to be "protective" against depression were not upon furthers statistical analysis. The first of these factors is a woman's employment status. This finding was slightly surprising as a woman's economic empowerment is oft-touted as a means to improve overall health (Hirani et al., 2010).

One possible explanation for these findings is that current or former employment seemed to be the norm for women rather than the exception in the study site, as urban areas are places where people often migrate to for work. It can hence be surmised that in an area like Islamabad with higher female baseline employment rates, employment status may not protect against or significantly contribute to a woman's risk for depression.

The next unexpected find was that neither marital status nor familial relationships independently influenced a woman's likelihood for depression. This was slightly surprising as marital status and familial relationships have often been discussed in the literature to protect women against depression (Javed, 2014; Khalily, 2011; Mirza and Jenkins, 2004).

These results are necessary to discuss because they highlight that strong family ties alone do not make women immune from depression. Depression is a nuanced disorder and must be treated as such. Important aspects of a woman's life like whether or not she owns her own home or how long she has been married impact her on a personal level, but these facts do not affect all women's personal wellbeing the same. For instance, some study participants reported they felt significant guilt and anguish as mothers as they blamed themselves for being the reasons their children suffered from diseases such as the poliovirus or became domestic houseworkers. For several other participants, family was the greatest joy in their lives, but ultimately did not protect them from this disease.

The most significant findings in this study, however, were those regarding women's healthcare behavior, access, and associations with depression likelihood. When a woman has depression, it is not only her own health that suffers, but also her ability to care for her family and contribute to society. In this study, women who screened positive for depression were 5.3 times more likely to report poor self-rated health. This statistic is particularly alarming given that self-rated health is a robust predictor of mortality globally, including amongst Pakistanis (Ahmad et al., 2005). It is hence unsurprising that study participants who were more likely to suffer from depression were also more likely to want to access healthcare. From a public health and economic perspective, effective treatment of depression will significantly decrease the burden on existing healthcare infrastructure, improve the economy, and substan- 
tially improve overall societal welfare. The economic burden of depression in the United States, for instance, has been estimated to cost the economy nearly $\$ 37$ billion annually (Lépine and Briley, 2011).

Furthermore, woman known to suffer from another medical condition had a $14 \%$ increased risk of clinical depression as compared to healthier women. This finding was expected as physical health problems are well-studied risk factors for emotional distress. Emotional distress can result in depression for patients, and numerous studies have further shown that depression is a major risk factor for a wide variety of other medical conditions, such as cardiovascular disease and stroke. When a woman suffers from depression, her ability to successfully be treated dwindles as well (Lyness, 2017; Kidwai, 2014; Naeem et al., 2003).

Unfortunately, despite a woman's desire to seek any form of healthcare, accessing either general healthcare or mental health treatment in Pakistan can be quite difficult; this proved to be true in as resource-rich of a region as Islamabad as well. While the vast majority of women struggled accessing care due to various reasons, this disparity was even larger amongst women with depression. Compared to their non-depressed counterparts, women with depression were nearly two to three times more likely to indicate feeling as if they did not deserve care or that it would not be effective, that they did not feel safe inside healthcare facilities, and that they viewed their mental health as a roadblock to accessing care. These findings indicate that further studies assessing the clinical care of depressed patients may be necessary to determine what extrinsic and intrinsic factors are hurting women's access to health so appropriate interventions can be made.

Additionally, only a minority of women reported having discussed their depressive symptoms with a healthcare provider; this indicates a suggestive treatment gap of up to $78 \%$. High depression treatment gaps have been discovered in other lower to middle income countries as well (Shah et al., 2014). Moreover, although multiple women said they had told a provider about their mental health, this data point must still be taken cautiously as no further data was collected on what type of healthcare provider the individual talked to, if any mental health care was provided, if the patient was being currently treated, and/or if the need for care was even recognized.

The fact that a minority of women still reported discussing their depressive symptoms begs the question of why many of these women had not been successfully treated, despite their frequent healthcare visits and the oft treatable nature of the disease (Cuijpers et al., 2013).

The reasons are potentially multi-fold. To start, while these women may be visiting healthcare facilities regularly, they are not necessarily receiving quality attention or intervention. A minority of women reported feeling belittled when talking to their provider, rushed in their healthcare visits, and disrespected when they saw their providers. Even when women visited low cost facilities, they recounted incidences of being denied further advice if they did not have money. These women also often belonged to the study's lowest income brackets. Their recounts of negative experiences are unsurprising as other studies have similarly found that patients belonging to poor economic groups and using government facilities face more discrimination in their healthcare than richer women and those able to afford private facilities (Nishtar et al., 2013).

Moreover, not all women surveyed used established healthcare facilities. 
Twelve reported that they rarely used established facilities or relied upon relatives, coworkers, and employers for their health advice. Overall, this implies that women may not be receiving adequate space or time to discuss their depressive symptoms and they potentially may not be discussing their illness with a certified healthcare worker. Another potential reason for the low treatment levels is that many healthcare workers in low and middle income nations like Pakistan may not be well trained to treat or even recognize depression. The availability of trained healthcare providers in Pakistan is thought to be insufficient across disciplines and there are very few mental health professionals in Pakistan overall (Nishtar et al., 2013).

Very little money is allocated towards mental healthcare by the government and overall funding is thought to lag significantly behind that of other health fields (Khalily, 2011). Further, even if women are being properly diagnosed and prescribed treatments, they may not be able to afford their required treatments or struggle in adhering to the care plan. Conducting further quality assessment and improvement research for mental healthcare is of the utmost importance.

There were further several important limitations in this pilot study. The first important limitation is that the period of data collection was limited and convenience sampling was utilized because of very high security concerns throughout Pakistan and especially within the I-8 sector. This limited sample size. However, many other Pakistani studies have also reported similar constraints in regards to not being able to randomly sample participants or having to limit their time collecting data due to safety concerns (Hamid et al., 2011; National Institute of Population Studies, 2013).
A second important limitation is that a cross-sectional design leaves little room for causal inference of factors on depression. A longitudinal study can provide greater information onto the temporality of these factors. These limitations can better be addressed in larger scale future studies.

This study adds significantly to currently available literature given the dearth of academic research on healthcare behavior, access, and its effects on mental health in conflict-afflicted regions, especially within South and Southwest Asia. The data collated provides an evidence-based starting model for identifying risk factors for various levels of depression amongst women living in high-risk urban areas, particularly within Pakistan. The most notable finding in this study was that even in highly developed urban areas within conflict-afflicted regions, the burden of depression amongst people-particularly women-may be alarmingly high.

Second, clinically depressed women may find it much more challenging to navigate the healthcare system, and may face barriers to access such as struggling to believe they deserve healthcare or that it will be effective for them. Consequently, it is likely that only a small minority of clinically depressed women in such regions have sought care or ever acknowledged their symptoms to a healthcare provider. Improving mental health disparities in urban settings throughout South and Southwest Asia will require not only increased screening and treatment of patients, but also removal of physical and psychological barriers faced in accessing care. Future studies should continue to assess the collective experiences within the healthcare system of patients with mental health in order to create effective and accessible interventions. Efforts should also be aimed at raising awareness about the vast prevalence of depression, its 
Haque et al./ Depression and healthcare barriers among urban Pakistani women

disabling consequences, and its highly treatable nature to ensure a healthier Pakistan for all.

\section{AUTHOR CONTRIBUTION}

Marina Haque spearheaded the study design, helped collate the data on ground, helped analyze the data, and wrote up the manuscript.

Alina Haque helped with study design, helped collate data on the ground, and helped write up the manuscript.

Allysha Choudhury primarily planned and ran statistical analysis of the data, drew most tables and graphs, interpreted results, and wrote up corresponding parts on the manuscript.

Roland Alexander Blackwood helped refine study design to meet specified objectives and ethical guidelines. He additionally suggested issues in the discussion.

\section{CONFLICT OF INTEREST}

The authors have no conflicts of interest.

\section{FUNDING AND SPONSORSHIP}

For the study, there is no official sponsor. There are no affiliated funders.

\section{ACKNOWLEDGEMENT}

Naz Haque, MD and Rasheeda Bano, MS for their substantial assistance with data collection.

\section{REFERENCE}

Ahmad K, Jafar TH, Chaturvedi N (2005). Self-rated health in Pakistan: results of a national health survey. BMC Public Health, 5(1): 51. https://doi.org/10.1186/1471-2458-5-51

Ahmer S, Faruqui RA, Aijaz A (2007). Psychiatric rating scales in Urdu: a systematic review. BMC Psychiatry, 7: 59. https://doi.org/10.1186/1471-244X-759
Ali TS, Mogren I, Krantz G (2013). Intimate partner violence and mental health effects: A population-based study among married women in Karachi, Pakistan. Int J Behav Med, 20(1): 131-139. https://doi.org/10.1007/s12529-011-9201-6

Cuijpers P, Sijbrandij M, Koole SL, Andersson G, Beekman AT, Reynolds CF (2013). The efficacy of psychotherapy and pharmacotherapy in treating depressive and anxiety disorders: A meta-analysis of direct comparisons. World Psychiatry, 12(2): 137-148. https://doi.org/10.1002/wps.20038

Geisser ME, Roth RS, Robinson ME (1997). Assessing depression among persons with chronic pain using the Center for Epidemiological Studies-Depression Scale and the Beck Depression Inventory: a comparative analysis. Clin $\mathrm{J}$ Pain, 13(2): 163-170. https://doi.org/10.1097/00002508-199706000-00011.

Government of Pakistan (2016). Pakistan 2016 Crime \& Safety Report: Islamabad.

Hamid S, Stephenson R, Rubenson B (2011). Marriage decision making, spousal communication, and reproductive health among married youth in Pakistan. Glob Health Action, 4: 5079. https://doi.org/10.3402/gha.v4io. 5079

Hirani SS, Karmaliani R, McFarlane J, Asad N, Madhani F, Shehzad S, Ali NA (2010). Development of an economic skill building intervention to promote women's safety and child development in Karachi, Pakistan. Issues Ment Health N/ 31(2): 82-88. https://doi.org/10.3109/01612840903254859.

Husain N, Creed F, Tomenson B (2000). Depression and social stress in 
Haque et al./ Depression and healthcare barriers among urban Pakistani women

Pakistan. Psychol Med, 30(2): 395402. https://doi.org/10.1017/s0033291700001707

Javed S (2014). Role of sociocultural factors in depression among elderly of twin cities (Rawalpindi and Islamabad) of Pakistan. Curr Gerontol Geriatr Res, 1-5. https://doi.org/10.1155/2014/230737

Lyness JM (2017). Unipolar depression in adults: Clinical features.

Karim S, Saeed K, Rana MH, Mubbashar MH, Jenkins R (2004). Pakistan mental health country profile. Int Rev Psychiatry, 16(1-2): 83-92. https://doi.org/10.1080/09540260310001635131.

Khalily MT (2011). Mental health problems in Pakistani society as a consequence of violence and trauma: a case for better integration of care. Int J Integr Care, 11(October): e128.

Khan A (1999). Mobility of women and access to health and family planning services in Pakistan. Reprod. Health Matters, 7(14): 39-48. https://doi.org/10.1016/So968-8080(99)900058.

Kidwai R (2014). Demographic factors, social problems and material amenities as predictors of psychological distress: A cross-sectional study in Karachi, Pakistan. Soc Psychiatry Psychiatr Epidemiol, 49(1): 27-39. https://doi.org/10.1007/s00127-013-0692-0

Lépine JP, Briley M (2011). The increasing burden of depression. Neuropsychiatr Dis Treat, 7(1): 3-7. https://doi.org/10.2147/NDT.S19617

Malakouti SK, Pachana NA, Naji B, Kahani S, Saeedkhani M (2015). Reliability, validity and factor structure of the CES-D in Iranian elderly. Asian J Psychiatr, 18, 86-90. https://doi.org/10.1016/j.ajp.2015.08.007
Mirza I, Jenkins R (2004). Risk factors, prevalence, and treatment of anxiety and depressive disorders in Pakistan: systematic review. BMJ (Clinical Research Ed.), 328(7443): 794. https://doi.org/10.1136/bmj.328.7443.794

Mumford DB, Minhas FA, Akhtar I, Akhter S, Mubbashar MH (2000). Stress and psychiatric disorder in urban Rawalpindi: Community survey. Brit J Psychiat, 177: 557-562. https://doi.org/10.1192/bjp.177.6.557

Naeem S, Ali B, Iqbal A, Mubeen A, Gul (2003). What probably made a difference? A qualitative study of anxious and depressed women who exhibited different levels of change after counselling. J Pakistan Med Assoc, 53(6).

National Institute of Population Studies. (2013). Pakistan Demographic and Health Survey 2012-13. Islamabad, Pakistan, and Calverton, Maryland, USA.

Nishtar S, Boerma T, Amjad S, Alam AY, Khalid F, Ul Haq I, Mirza YA (2013). Pakistan's health system: Performance and prospects after the 18th Constitutional Amendment. The Lancet, 381 (9884): 2193-2206. https://doi.org/10.1016/So140-6736(13)60019-7

Qadir F, Khan MM, Medhin G, Prince M, Mumford D, Minhas F, et al. (2011). Male gender preference, female gender disadvantage as risk factors for psychological morbidity in Pakistani women of childbearing age - a life course perspective. BMC Public Health, 11(1): 745. https://doi.org/10.1186/1471-2458-11-745

Radloff LS (1977). The CES-D Scale: A SelfReport Depression Scale for Research in the General Population. Appl Psychol Meas, 1(3): 385-401. https://doi.org/10.1177/014662167700100306. 
Haque et al./ Depression and healthcare barriers among urban Pakistani women

Rahman A, Iqbal Z, Waheed W, Hussain N (2003). Translation and cultural adaptation of health questionnaires. $\mathrm{J}$ Pakistan Med Assoc. 53(4): 142-147.

Reza H, Khan MM (2003). Depressive disorder: Diagnosis and management in general practice in Pakistan. J Pak Med Assoc. 53(10): 500-505.

Shah S, Van Den Bergh R, Van Bellinghen B, Severy N, Sadiq S, Afridi SA, et al. (2014). Offering mental health services in a conflict affected region of Pakistan: Who comes, and why? PLoS ONE, 9(6). https://doi.org/10.1371/journal.pone.oo97939

Shaikh S, Memon S, Ahmed I, Manzoor AR, Shaikh S (2014). Impact of an IEC (information, education and communication) intervention on key family practices of mothers related to child health in Jamshoro, Sindh. Pakistan J Med Sci. 30(3). https://doi.org/10.12669/pjms.303.4798

Thomas JL, Jones GN, Scarinci IC, Mehan DJ, Brantley PJ (2001). The utility of the CES-D as a depression screening measure among low-income women attending primary care clinics. The Center for Epidemiologic StudiesDepression. Int J Psychiat Med, 31(1), 25-40. https://doi.org/10.2190/FUFR-PK9F-6U10-JXRK. 